\title{
Temporal discrimination using different feature-target intervals in classical conditioning of the rabbit's nictitating membrane response
}

\author{
E. J. KEHOE and K. G. BOESENBERG \\ University of New South Wales, Sydney, New South Wales, Australia
}

\begin{abstract}
In a typical conditional discrimination, a target stimulus $(\mathrm{X})$ is reinforced during one feature cue $(\mathrm{A} \rightarrow \mathrm{X}+)$, but not during another feature cue $(\mathrm{B} \rightarrow \mathrm{X}-)$. The present experiments used only a single "feature" cue (a 66-sec tone). On half of the trials, the target stimulus (a 400-msec light) was paired with the reinforcer when the feature-target interval was one duration (e.g., $5 \mathrm{sec}$ ). On the remaining trials, the interval was different (e.g., $45 \mathrm{sec}$ ), and the target stimulus was presented without the reinforcer. All the animals acquired this temporal discrimination, and subsequent testing with other feature-target intervals yielded generalization-like gradients. These results provide solid evidence that each portion of a feature cue is encoded in a distinctive fashion. Had temporal encoding not occurred, the feature cue would have been just as ambiguous a predictor of the reinforcer as was the target stimulus, and discrimination would not have been possible. The integration of real-time temporal encoding mechanisms into models of conditional discrimination is discussed.
\end{abstract}

In a conditional discrimination, a brief target stimulus $(\mathrm{X})$ is reinforced in the presence of one feature cue $(\mathrm{A} \rightarrow \mathrm{X}+)$ but is not reinforced in the presence of another feature cue $(\mathrm{B} \rightarrow \mathrm{X}-)$. The durations of feature cues prior to the target stimulus have been manipulated over a huge range. In some cases, the feature cues have been only a few hundred milliseconds (Weidemann, Georgilas, \& Kehoe, 1999). In other cases, the feature cues have filled the entire feature-target interval and beyond (e.g., Brandon \& Wagner, 1991; Kehoe, Palmer, Weidemann, \& Macrae, 2000; Kimmel \& Ray, 1978; Weidemann \& Kehoe, 1997). In conditioning of the rabbit nictitating membrane (NM) response, for example, conditional discriminations have been readily acquired by using feature cues for which $61 \mathrm{sec}$ have elapsed between their onset and the onset of a 400-msec target stimulus (Macrae \& Kehoe, 1995). Finally, static features of different conditioning chambers present for an entire training session have been used as conditional cues in establishing discriminative responding to a target stimulus (Asratyan, 1965; Bouton, 1991; Grahame, Barnet, \& Miller, 1992; Grahame, Hallam, Geier, \& Miller, 1990).

The ability to establish conditional discriminations with such a wide range of feature-target intervals has suggested that the feature cues and the target stimulus have different roles. In general, feature cues are thought

Preparation of this manuscript was supported by Australian Research Council Grant A79800067. The authors thank Benjamin Carr, Miriam Smith, Gabrielle Weidemann, and Natasha E. White for their assistance in collecting data and preparing the manuscript. Correspondence should be sent to E. J. Kehoe, School of Psychology, University of New South Wales, Sydney, NSW 2052, Australia (e-mail: j.kehoe@unsw.edu.au). to signal whether or not the reinforcer will occur. The target stimulus, on the other hand, is thought to signal when the reinforcer will occur and to control the acquisition of the conditioned response (CR) according to contiguity-based processes. Hence, a variety of theories postulate a special type of associative process in which feature cues do not directly elicit the CR but modulate the expression of the CR to the target stimulus (e.g., Brandon \& Wagner, 1991; Holland, 1983, 1992; Rescorla, 1985; Wagner \& Brandon, 1989).

Although the feature-target interval might appear to exercise little influence on conditional discriminations, there is now solid evidence that conditional responding has temporal specificity. When the feature-target interval has been manipulated on test trials, distinct gradients in responding have appeared in both rabbits and rats (Holland, Hamlin, \& Parsons, 1997; Kehoe et al., 2000). Specifically, responding to the target stimulus progressively declined as the feature-target interval for the positive cue $(\mathrm{A} \rightarrow \mathrm{X}+)$ was shifted away from the value used in training.

These gradients strongly resemble stimulus generalization gradients. The resemblance is so compelling that it is hard to imagine a plausible alternative to the hypothesis that successive portions of a feature cue are encoded along a time-dependent dimension (Barnet \& Miller, 1996; Kehoe et al., 2000; Savastano \& Miller, 1998). If this hypothesis is true, it should be possible to produce a conditional discrimination solely on the basis of temporal cues arising from the feature cue. To test this crucial deduction, we conducted the following experiments, using only a single feature cue (a 66-sec tone), as well as a single target stimulus (a $400-\mathrm{msec}$ light). The 
target stimulus was paired with the reinforcer when the feature-target interval was one duration (e.g., $5 \mathrm{sec}$ ). On the other trials, however, the interval was different (e.g., $45 \mathrm{sec}$ ), and the target stimulus was presented without the reinforcer. Because the feature cue and the target stimulus were always the same from one trial to the next, the only basis for discriminative responding to the target stimulus was the different feature-target intervals.

\section{EXPERIMENT 1}

The aim of Experiment 1 was to determine whether a temporal discrimination could be established with two different feature-target intervals. To provide converging evidence that the discriminative responding had temporal specificity, tests were conducted with other feature-target intervals that were shorter, longer, and intermediate to the two values used in training.

\section{Method}

\section{Subjects}

The subjects were 16 female albino rabbits (Oryctolagus cuniculus), approximately 12 weeks old on arrival from the supplier. All were housed in individual cages and had unlimited access to food and water.

\section{Apparatus}

The apparatus and the recording procedure for the NM response were patterned after those described by Gormezano (1966). The rabbits were trained individually in one of eight sound-attenuating chambers. On the wall of each chamber in front of the subject was a stimulus panel. A speaker was mounted at the midpoint of the stimulus panel, $8 \mathrm{~cm}$ anterior to and $16 \mathrm{~cm}$ above the rabbit's head. The speaker provided the feature cue (A), which was a 66-sec, $1000-\mathrm{Hz}, 88-\mathrm{dB}$ (SPL) tone superimposed on an ambient noise level of $81 \mathrm{~dB}$, which was produced by an exhaust fan situated behind each subject. Mounted on the stimulus panel, $4 \mathrm{~cm}$ above the speaker, was an 8 -W neon light that served as a houselight. The target stimulus (X) was a 400-msec, 20-Hz flashing of the houselight. The unconditioned stimulus (US) was a 50-msec, 4-mA, 50-Hz AC current delivered via stainless steel Autoclip wound clips were positioned $10 \mathrm{~mm}$ apart and $15 \mathrm{~mm}$ posterior to the dorsal canthus of the rabbit's right eye. The stimulus events and the response recording were controlled by an Apple II computer equipped with interfaces and software developed by Scandrett and Gormezano (1980).

During training, each rabbit was restrained in a Perspex box $(45 \times 14 \times 22 \mathrm{~cm})$ and was held in place by inserting its head through an adjustable stock and securing its ears to the front of the stock with a polyurethane foam-covered metal clamp. A muzzlelike headset, fitted securely about the snout, supported a photoelectric transducer for detecting movements of the NM (Gormezano \& Gibbs, 1988). A small hook was attached to a silk loop sutured into the NM of the rabbit's right eye. The hook was connected to one end of an L-shaped crank that operated the photoelectric transducer. The signal from the transducer was amplified and transmitted to an analog-to-digital converter mounted in the computer.

\section{Procedure}

All the rabbits received 1 day of preparation and 1 day of adaptation before training began. On the preparation day, hair posterior to each rabbit's right eye was removed, the rabbits had their right eye anesthetized (Opthaine), and a small loop of surgical silk (000
Dynex) was sutured into the NM of the right eye. The rabbits were then returned to their home cages. On the adaptation day, the rabbits were placed in the conditioning apparatus for $60 \mathrm{~min}$, but no stimuli were programmed.

Phase 1: Temporal discrimination training. Following adaptation, the rabbits were randomly assigned to two groups $(n=8)$. Both groups were given 11 days of training in the temporal discrimination task. Each day included 15 reinforced trials $(\mathrm{A} \rightarrow \mathrm{X}+)$ and 15 nonreinforced trials $(\mathrm{A} \rightarrow \mathrm{X}-)$. The reinforced trials differed from the nonreinforced trials only in the interval between the onset of the feature cue and the onset of the target stimulus. One group was designated as Group 5+. In that group, the target stimulus was paired with the US when the feature-target interval was $5 \mathrm{sec}$, and the target stimulus was presented alone at the 45 -sec interval. The other group was designated as Group 45+, in which the US was delivered at the 45 -sec interval and not at the 5-sec interval. On reinforced trials, the CS-US interval between the onset of the target stimulus and the onset of the US was $400 \mathrm{msec}$. Trials were presented in a random order, with the exception that no more than 3 trials of the same type occurred consecutively. The intertrial interval (ITI) between the offset of the feature cue and its next onset was $66 \mathrm{sec}$. The total duration of each training session was $66 \mathrm{~min}$.

Phase 2: Feature-target interval testing. Both groups underwent three test sessions. These took place on Days 12, 13, and 15. (Day 14 was a retraining day identical to those in Phase 1.) In each test session, the rabbits were presented with 18 nonreinforced test trials. These consisted of 3 trials each with feature-target intervals of $0,5,25,45$, and $65 \mathrm{sec}$, plus 3 trials of the feature cue (A) alone. On these test trials, the duration of the feature cue (A) remained fixed at $66 \mathrm{sec}$, as it had been on training trials. Hence, the target stimulus was always tested while the feature cue was present. There were also 9 reinforced training trials and 6 nonreinforced training trials identical to those used in Phase 1. The presentation of all the trials occurred on a random basis, with the only exception being that no more than 3 trials of the same type occurred consecutively. The ITI was $66 \mathrm{sec}$, and the total duration of each test session was $73 \mathrm{~min}$.

\section{Response Definition}

A CR was defined as any extension of the NM exceeding $0.5 \mathrm{~mm}$ that occurred during a 400-msec period following the onset of the target stimulus. In addition, CRs were counted if they occurred within $400 \mathrm{msec}$ of the onset of the feature cue.

\section{Results}

Statistical comparisons were conducted according to the method for analyzing repeated measures designs described by O'Brien and Kaiser (1985). The rejection level was set according to a Type 1 error rate of .05.

\section{Phase 1: Acquisition of Temporal Discrimination}

Figure 1 depicts the mean CR likelihood $( \pm 1.96 \mathrm{SE})$ during the target stimulus (X) on each of the 11 days of acquisition. Responses made by Group 5+ are displayed in the upper panel, and responses made by Group 45+ are displayed in the lower panel. Inspection of Figure 1 reveals that both groups acquired differential responding to the reinforced versus nonreinforced presentations of the target stimulus $\left[F(1,14)=80.66, M S_{\mathrm{e}}=1,936, p<\right.$ .01]. By the end of training, all the animals in both groups showed a higher $C R$ likelihood to $X$ in $A \rightarrow X+$ trials than in $\mathrm{A} \rightarrow \mathrm{X}-$ trials. However, acquisition of con- 

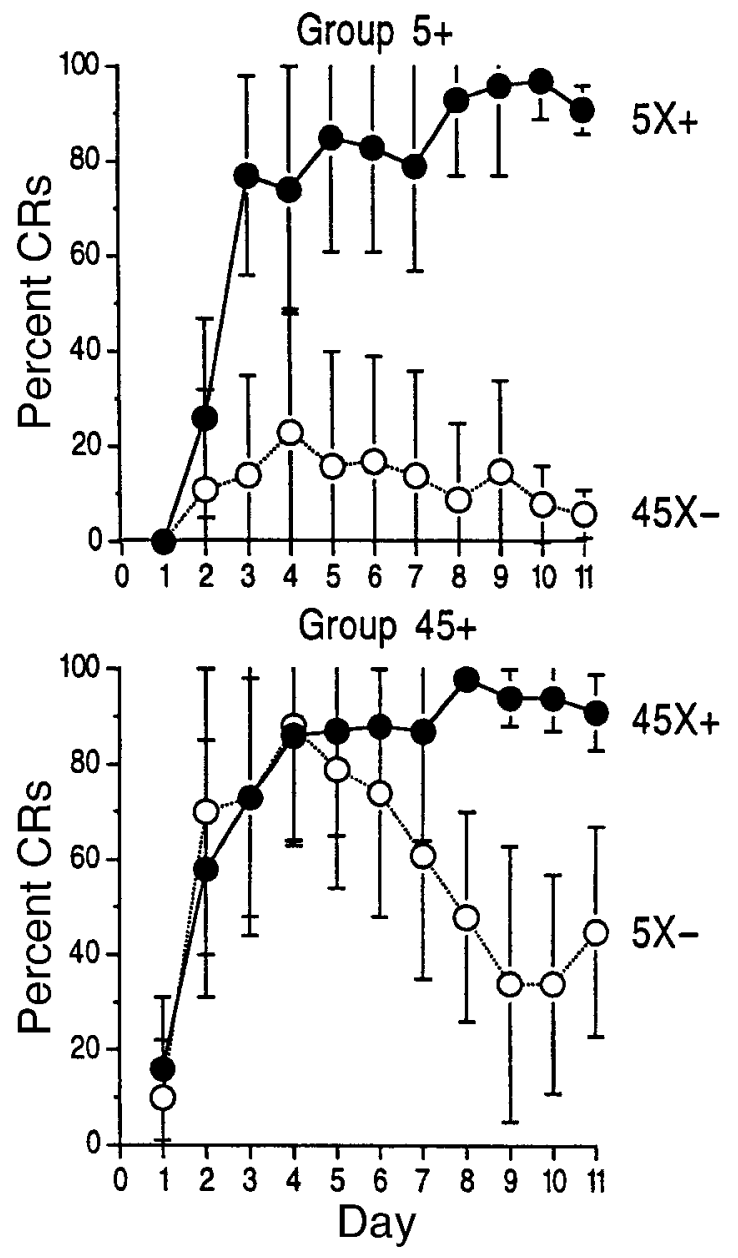

Figure 1. Mean conditioned response $(C R)$ likelihood $( \pm 1.96$ $S E)$ during the target stimulus $(X)$ at the reinforced versus nonreinforced feature-target intervals as a function of days in Groups 5+ and 45+ in Phase 1 of Experiment 1.

ditional control differed between the two groups $[F(1,14)=$ $\left.16.04, M S_{\mathrm{e}}=1,936, p<.01\right]$. Group $5+$ showed a rapid and large differentiation in responding to the target stimulus. In contrast, Group 45+ initially showed a rise in responding to the target stimulus at both the reinforced and the nonreinforced intervals. Beginning on Day 5, responding to the target stimulus at the 5-sec nonreinforced interval started dropping away. On the last day of training, both groups responded at a mean level of $91 \%$ CRs on $\mathrm{A} \rightarrow \mathrm{X}+$ trials. On $\mathrm{A} \rightarrow \mathrm{X}-$ trials, Group 5+ showed 6\% CRs, whereas Group 45+ showed 45\% CRs. Post hoc tests confirmed that significant differential responding was established in both Group $5+[F(1,14)=84.31$, $\left.M S_{\mathrm{e}}=1,936, p<.01\right]$ and Group $45+[F(1,14)=12.38$, $\left.M S_{\mathrm{e}}=1,936, p<.01\right]$.

In addition to conditional responding during the target stimulus, both groups showed some CRs to the onset of the feature cue (A). As measured during the first $400 \mathrm{msec}$ following A onset, both groups showed CRs that reached a maximum likelihood of $18 \%(1.96 S E=$ $13 \%$ ) by Day 4 . Thereafter, responding dwindled to $4 \%$ (1.96 SE $=4 \%$ ) by Day 11. Statistical comparisons confirmed that there was a significant downward linear trend $\left[F(1,14)=7.46, M S_{\mathrm{e}}=701, p<.05\right]$. No differences related to groups or the type of trial (reinforced vs. nonreinforced) were apparent $\left(F_{\mathrm{S}}<1\right)$.

\section{Phase 2: Feature-Target Interval Gradients}

Figure 2 shows the mean CR likelihood $( \pm 1.96 S E)$ during the target stimulus as a function of the feature-target intervals used in the test sessions. For Group 5+, the maximum level of responding appeared at the 5-sec featuretarget interval that had been used on reinforced training trials. As the test interval deviated from the training interval, responding during the compound declined sharply to a level of less than $10 \%$ CRs at the 45 -sec and 65 -sec test intervals. Statistical comparisons confirmed that there was a significant linear trend in responding across feature-target intervals $\left[F(1,14)=12.04, M S_{\mathrm{e}}=\right.$ $823, p<.01]$, but not a quadratic trend $[F(1,14)=1.85$, $\left.M S_{\mathrm{e}}=152, p<.05\right]$. Post hoc tests were conducted to determine whether responding to the target stimulus at the 5 -sec test interval was higher than that at the adjacent intervals. The difference between the 5-sec interval and the 0 -sec interval approached but did not reach statistical significance $\left[F(1,14)=4.04, M S_{\mathrm{e}}=551, p<.05\right]$, but the difference between the 5 -sec interval and the $25-\mathrm{sec}$ interval did $\left[F(1,14)=9.65, M S_{\mathrm{e}}=584, p<.01\right]$.

Group 45+'s gradient appears to be a mirror image to that of Group 5+'s gradient. That is, the minimum level of responding occurred at the 5-sec feature-target interval, which was not reinforced in training. A high level of responding occurred at the 45-sec interval used on reinforced training trials, but also at the 65 -sec test interval. Statistical comparisons revealed a significant linear

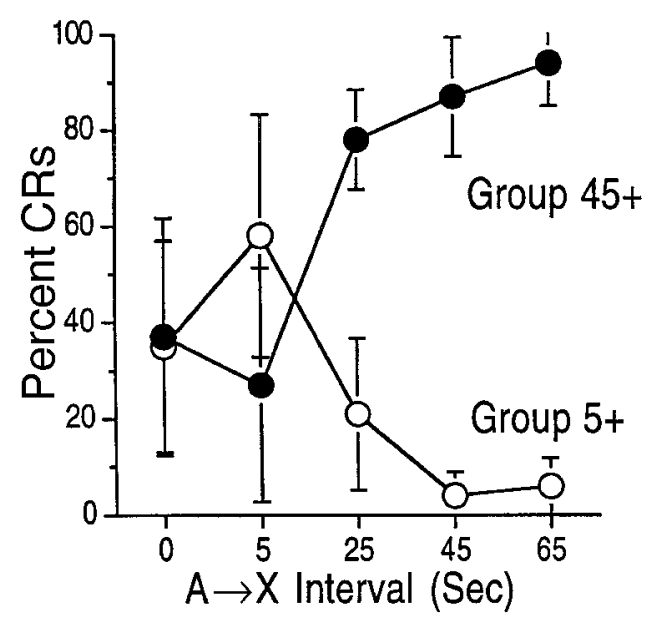

Figure 2. Mean conditioned response $(C R)$ likelihood $( \pm 1.96$ $S E$ ) during the target stimulus $(X)$ as a function of the featuretarget interval during testing in Phase 2 of Experiment 1. 
trend across feature-target intervals $[F(1,11)=28.88$, $\left.M S_{\mathrm{e}}=823, p<.01\right]$, but not a quadratic trend $(F<1)$. Post hoc tests were conducted to determine whether responding to the target stimulus at the 5-sec test interval was less than that at the adjacent intervals. The apparent difference between the 5-sec interval and the 0 -sec interval did not even approach significance $(F<1)$, but the difference between the 5-sec interval and the 25 -sec interval was significant $\left[F(1,14)=17.63, M S_{\mathrm{e}}=551, p<\right.$ .01]. A final test as to whether responding at the $45-\mathrm{sec}$ interval was less than that at the 65-sec interval approached but did not reach the conservative criterion for post hoc tests $\left[F(1,14)=5.28, M S_{\mathrm{e}}=36, p<.05\right]$.

To determine whether responding to the feature cue in Phase 2 contributed to responding during the target stimulus, particularly when their onsets were simultaneous at the 0 -sec test interval, the likelihood of a CR during the first $400 \mathrm{msec}$ of A-alone presentations was examined. In fact, responding to the onset of the feature cue was negligible. CR likelihood following the onset of $\mathrm{A}$ in both groups was $1 \%(1.96 S E=1 \%)$.

\section{Discussion}

Experiment 1 demonstrated that a conditional discrimination could be acquired with time-related cues provided by the feature-target interval. In addition, the gradients that appeared in Phase 2 complement the gradients obtained after conventional conditional discriminations (Holland et al., 1997; Kehoe et al., 2000). Together, the results from Phases 1 and 2 provide converging evidence that successive portions of the feature cue are encoded in a distinctive fashion.

The appearance of CRs to the onset of the feature cue in both groups is consistent with the results of previous rabbit NM studies that have entailed the presentation of two conditioned stimuli (CSs) in sequence prior to the US $(\mathrm{A} \rightarrow \mathrm{X}+$; Kehoe, Gibbs, Garcia, \& Gormezano, 1979; Kehoe, Marshall-Goodell, \& Gormezano, 1987; Kehoe et al., 2000; Schreurs, Kehoe, \& Gormezano, 1993). The primary mechanism for the initial acquisition of CRs to a feature cue appears to be higher order conditioning between the A and the X stimuli (Gibbs, Cool, Land, Kehoe, \& Gormezano, 1991; Gibbs, Kehoe, \& Gormezano, 1991; Kehoe, Feyer, \& Moses, 1981). In both groups, responding to the onset of the feature cue gradually declined and reached negligible levels by the time of Phase 2 testing. This ultimate loss of responding to the feature cue has also been seen previously in studies in which serial stimuli were used and, in descriptive terms, may be a form of inhibition of delay (Kehoe et al., 1979).

The evidence of excitatory conditioning to the onset of the feature cue early in Phase 1 may help explain the shape of the Phase 2 gradient in Group 45+. At the featuretarget intervals of 0,5 , and $25 \mathrm{sec}$, the CR likelihood during the target stimulus in Group 45+ assumed a V-shaped pattern. This pattern could indicate that the nonrein- forced 5-sec feature-target interval had acquired an inhibitory value. Statistically, the higher level of responding at the 0 -sec interval versus the 5-sec interval was not significant and, hence, may well have resulted from sampling errors at either or both points. Even if the difference had been statistically significant, there is a plausible alternative hypothesis to an inhibitory hypothesis: Responding during $\mathrm{X}$ at the 0 -sec test interval may have reflected summation of its excitatory value with the excitatory value of A's onset. Although responding to A's onset had disappeared by the time of testing, there may have been enough residual excitation to summate with X.

\section{EXPERIMENT 2}

Experiment 2 had three aims. In descending order of importance, they were the following.

1. Experiment 2 was intended to replicate the acquisition of the temporal discrimination seen in Experiment 1 when the longer of the two feature-target intervals was reinforced, as in Group 45+. That group had some difficulty in acquiring the discrimination. Responding on nonreinforced trials initially rose, along with responding on reinforced trials, before differential responding began to appear.

2. Experiment 2 was intended to determine whether the gradients seen in Experiment 1 require temporal discrimination training. In previous demonstrations of temporal specificity, gradients appeared when only a single feature-target interval was used for each feature cue. Accordingly, Experiment 2 included a control group that received reinforced training with only the longer featuretarget interval. On nonreinforced trials, the control group received the feature cue alone, without either the target stimulus or the reinforcer. This control group would have an excitatory association established only at the longer interval. If temporal encoding of the feature cue does not rely on differential reinforcement, this group was expected to show a gradient similar to that seen in the temporal discrimination group.

3. In Experiment 1, there was some evidence of a V-shaped gradient in Group 45+. Apart from likely sampling errors, this gradient may have resulted either from the establishment of an inhibitory association along the feature cue's temporal dimension or from summation of excitatory tendencies of the feature cue's onset with those of the target stimulus at the 0 -sec test interval. To help test these alternative hypotheses, the feature-target intervals during training were changed from 5 and $45 \mathrm{sec}$ to values of 10 and $40 \mathrm{sec}$. By closing the interval, there would be greater excitatory generalization to the nonreinforced interval, thus raising the background level of excitation against which inhibition could be acquired. These changes were also intended to provide better temporal resolution in the gradients generated during interval testing. In particular, the increase in the shorter featuretarget interval allowed a 5-sec interval to be used as a test 

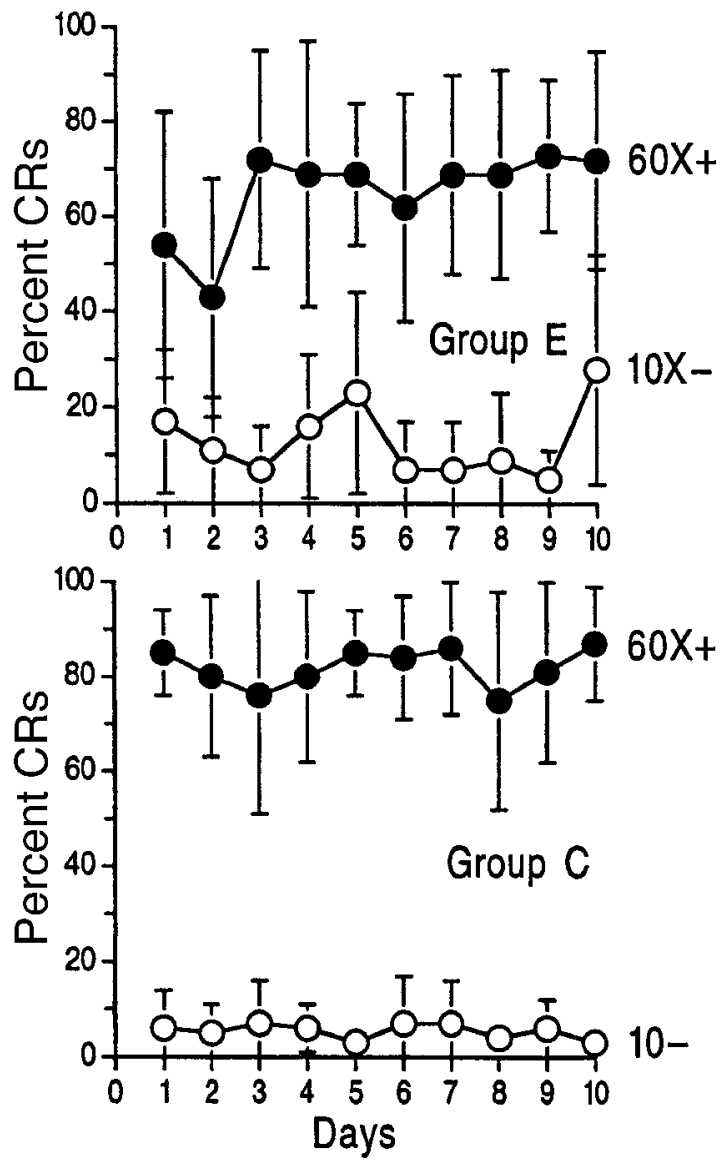

Figure 3. Mean conditioned response (CR) likelihood $( \pm 1.96$ $S E$ ) during the target stimulus $(X)$ at the reinforced versus nonreinforced feature-target intervals as a function of days in Group E during the last 10 days in Phase 1 of Experiment 2. For Group $C$, a period corresponding to the target stimulus was measured on nonreinforced A-alone trials.

point intermediate between the 0 -sec test interval and the 10 -sec interval used in training. However, as will be reported, the 10 - and $40-\mathrm{sec}$ intervals proved to be too close to promote differential responding. Hence, during the course of the experiment, the longer feature-target interval was increased to $60 \mathrm{sec}$. This increase allowed conditional discrimination learning to proceed and still permitted testing at the $0-, 5-$, and 10 -sec intervals.

\section{Method}

Subjects

The subjects were 16 naive albino rabbits.

\section{Apparatus and Procedure}

The apparatus and procedure for Experiment 2 were the same as those described for Experiment 1, unless otherwise indicated. The rabbits were randomly assigned to two groups $(n=8)$. Each group was run in two replications. One animal in the first replication of Group E was removed as a result of illness early in the experiment, reducing Group E to 7 animals.
Phase 1: Temporal discrimination training. The temporal discrimination group was designated as Group E. In its first replication, it received 11 days of training, in which the reinforced featuretarget interval was $40 \mathrm{sec}$ and the nonreinforced feature-target interval was $10 \mathrm{sec}$. However, these intervals failed to produce discriminative responding. In fact, there was hardly any CR acquisition at all. After 11 days of training, CR likelihood during the target stimulus was only $22 \%$ on reinforced trials and $0 \%$ on nonreinforced trials. The reinforced feature-target interval was then extended to $60 \mathrm{sec}$, and training was continued another 11 days. In the second replication of Group E, the 60-sec reinforced feature-target interval was used from the start of Phase 1 training, which lasted for 20 days. In both replications, the nonreinforced feature-target interval was always $10 \mathrm{sec}$.

The control group was designated as Group C. In its first replication, it received the 40 -sec reinforced feature-target interval for 11 days, and then it received the 60 -sec reinforced feature-target interval for another 11 days. In the second replication, Group $\mathrm{C}$ received 20 days of training with the 60 -sec reinforced feature-target interval. In both replications of Group $\mathrm{C}$, nonreinforced trials entailed presentations of the feature cue alone.

In both groups, all the training sessions contained 15 reinforced trials and 15 nonreinforced trials. The presentation of trials occurred on a random basis, with the restriction that no more than 3 trials of the same type were presented in succession. The ITI was $66 \mathrm{sec}$, and the total duration of each session was $66 \mathrm{~min}$.

Phase 2: Interval testing. Phase 2 contained 3 days of testing interspersed with 2 days of retraining. Test trials were presented at feature-target intervals of $0,5,10,30$, and $60 \mathrm{sec}$. These trials were not reinforced by the US. There were three test presentations of each feature-target interval. These were intermixed with nine reinforced presentations of the 60 -sec feature-target interval and nine nonreinforced presentations of the 10 -sec feature-target interval. The presentation of all the trials occurred on a random basis, with the restriction that no more than three trials of the same type were presented in succession. The ITI was $66 \mathrm{sec}$, and the total duration of each test session was $73 \mathrm{~min}$.

\section{Results}

\section{Phase 1: Acquisition of Temporal Discrimination}

Figure 3 shows the mean CR likelihood during the target stimulus (X) during the last 10 days of Phase 1. The means for each group are pooled across replications, because the main effect and interactions relating to replications were small and did not even approach statistical significance $\left(F_{\mathrm{S}}<1\right)$.

The top panel shows the asymptotic levels of responding $( \pm 1.96 S E)$ on reinforced versus nonreinforced trials in Group E, which differed significantly $[F(1,5)=$ $\left.62.21, M S_{\mathrm{e}}=1,489, p<.01\right]$. On the training days prior to reaching the levels shown in Figure 3, both replications of Group E showed conditional responding as soon as CRs began to appear. Responding to the target stimulus at the reinforced 60 -sec feature-target interval rose steadily toward its asymptote of $70 \%$ CRs. Responding to the target stimulus at the $10-\mathrm{sec}$ nonreinforced interval settled at an asymptote of around $20 \%$ CRs, albeit with considerable variability. By the end of training, all the animals in Group E showed a higher CR likelihood to $\mathrm{X}$ in $\mathrm{A} \rightarrow \mathrm{X}+$ trials than in $\mathrm{A} \rightarrow \mathrm{X}-$ trials.

The bottom panel shows the results for Group C, which received presentations of the target stimulus only at the 60 -sec feature-target interval. As can be seen, CR likeli- 
hood during the target stimulus showed a stable asymptote of around $80 \% \mathrm{CRs}$. In the same panel, the lower line shows the likelihood of a response during the 400-msec portion of the feature cue corresponding to the target stimulus at the 10-sec feature-target interval in Group E. The likelihood of a response during this period averaged around 5\% CRs, which matches the rate of spontaneous blinking in the rabbit NM preparation.

Responding to the feature cue was assessed during the first $400 \mathrm{msec}$ following A onset on training trials. By the end of Phase 1 and throughout Phase 2, CRs to A onset were rare. In Groups $\mathrm{E}$ and $\mathrm{C}$, the mean CR likelihoods were $0 \%$ and $0.5 \%(1.96 S E=0.3 \%)$.

\section{Phase 2: Feature -Target Interval Gradients}

Figure 4 shows the mean CR likelihood $( \pm 1.96 S E)$ during the target stimulus as a function of the featuretarget interval. Inspection of the figure reveals that both groups showed a similar pattern. The highest CR likelihood appeared at the 60-sec feature-target interval that was reinforced in training. At shorter intervals, CR likelihood progressively declined. There were significant linear and quadratic trends in responding as a function of test interval $\left[F_{\mathrm{s}}(1,13)=31.06\right.$ and $13.61, M S_{\mathrm{e}}=587$ and $419, p$ s $<.01]$. The only noticeable difference between the two groups was in their overall level. Group E showed a significantly lower level of responding than Group $\mathrm{C}$ at all test intervals $\left[F(1,13)=5.08, M S_{\mathrm{e}}=2,311, p<.05\right]$. Unlike the V-shaped curve produced by Group $45+$ in Experiment 1, Group E showed little evidence of a depression in responding at the 10 -sec test interval.

\section{Discussion}

The results of Experiment 2 achieved its primary aim-namely, confirming that a conditional discrimina-

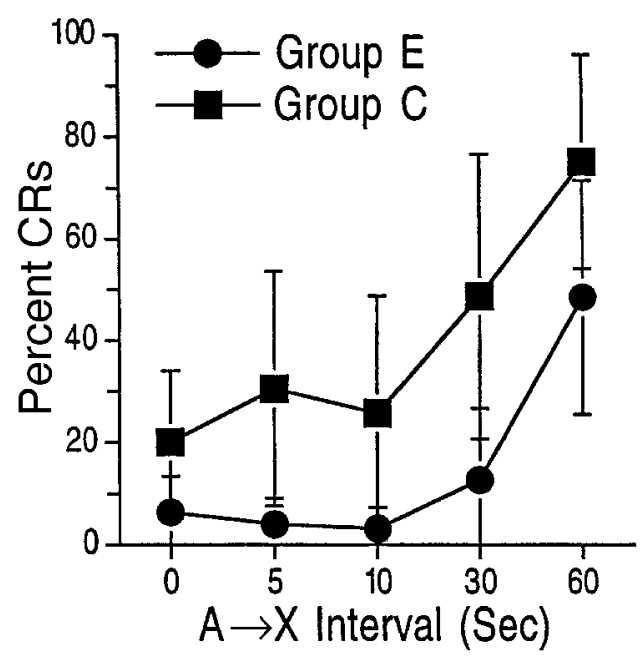

Figure 4. Mean conditioned response $(\mathrm{CR})$ likelihood $( \pm 1.96$ $S E$ ) during the target stimulus $(X)$ as a function of the featuretarget interval during testing in Phase 2 of Experiment 2. tion could be acquired on the basis of different featuretarget intervals. This discrimination, however, depended on there being a relatively large difference in the two intervals. A difference of $30 \mathrm{sec}$ between the $10-\mathrm{sec}$ and the 40-sec intervals failed to produce discriminative responding, whereas a difference of $50 \mathrm{sec}(10 \mathrm{vs} .60 \mathrm{sec})$ did yield a discrimination. In fact, when the difference was increased to $50 \mathrm{sec}$, the acquisition of the discrimination proceeded in Group $\mathrm{E}$ more rapidly than it did in Group 45+ in Experiment 1, in which difference between the nonreinforced interval $(5 \mathrm{sec})$ and the reinforced interval $(45 \mathrm{sec})$ was $40 \mathrm{sec}$. Although there were other differences between Group E and Group 45+, their combined results roughly indicate the range of differences $(30-50 \mathrm{sec})$ that produce large changes in temporal conditional discriminations in the rabbit NM preparation.

Experiment 2 also achieved its secondary aim of determining whether the gradients of temporal specificity require temporal discrimination training. The answer is no. Both Groups E and C showed parallel decremental gradients when the feature-target interval was reduced from the 60 -sec reinforced interval. This finding converges with the gradients obtained using conventional conditional discriminations, in which only a single featuretarget interval is used for both feature cues (Kehoe et al., 2000).

With respect to the third aim of Experiment 2, the V-shaped gradient seen with Group 45+ in Experiment 1 did not appear with Group E. The gradient in CR likelihood for different feature-target intervals for Group E fell off smoothly and did not show a depression at the 10 -sec test interval. Moreover, Group C, which could not have developed an inhibitory association at the $10-\mathrm{sec}$ feature-target interval, showed a similar smooth gradient. At this point, the safest interpretation of the original V-shaped gradient in Group 45+ is that it was a sampling error. At best, the V-shaped gradient depended on highly restricted conditions that were not duplicated in Group E. For example, the 10-sec feature-target interval may not have been conducive to second-order conditioning.

\section{GENERAL DISCUSSION}

The present results provide strong support for the hypothesis that successive portions of a feature cue are encoded along some time-dependent dimension (Barnet \& Miller, 1996; Kehoe et al., 2000; Savastano \& Miller, 1998). The present results also diminish the sharp distinction between the roles of the feature cue and the target stimulus as global events in controlling the CR. By using only a single feature cue, as well as a single target stimulus, both events had parallel roles in predicting the US. At the onset of the feature cue, the probability of the US was always .5. Likewise, the target stimulus by itself was an equally ambiguous predictor of the US. However, by incorporating temporal encoding mechanisms for feature cues, the present results can be accommodated with 
various degrees of success by alternative theories of conditional discrimination. In broad terms, there are three major theoretical approaches.

Modulation theories focus on feature cues as signals for the US. They propose that a positive feature cue becomes associated with the emotional attributes of the US, whereas the target stimulus becomes associated with the sensory-perceptual attributes of the US (e.g., Brandon \& Wagner, 1991; Konorski, 1967). The association with emotive aspects of the US produces a diffuse, preparatory activity that energizes discrete CS-US associations but does not itself elicit CRs. These theories would have considerable difficulty in explaining the present findings, because they assume that preparatory conditioning has wide temporal boundaries. These theories can be saved by narrowing the temporal boundaries for preparatory conditioning, perhaps to a range of several seconds surrounding the temporal locus of the US. This reduction would still leave intact the key prediction of such theories that preparatory conditioning of a feature cue should transfer to CSs that have not been targets in conditional discriminations.

Hierarchical theories focus on feature cues as signals for the target stimulus. These theories assert that the feature cue acquires a relatively specific relationship with the target cue. Through this relationship, the feature cue acts to retrieve or facilitate the target-US association, without gaining a direct association with the US or the ability to directly elicit the CR (Holland, 1983, 1992; Rescorla, 1985). Like the modulation theories, the hierarchical theories have tended to assume that serial featuretarget relationships have wide temporal boundaries, which now would have to be reduced.

Configural theories focus on feature cues in the direct elicitation of CRs (e.g., James \& Wagner, 1980; Kehoe et al., 1987). These theories assume that the feature cue is integrated with the target stimulus into a joint representation through a process of immediate perceptual fusion (Gluck \& Bower, 1988; Pearce, 1987, 1994; Rescorla, 1973; Whitlow \& Wagner, 1972) or through a learned synthesis (Kehoe, 1998; Konorski, 1967, pp. 64-66, 75, 86; Razran, 1971, p. 265). In turn, this joint representation becomes associated directly with the US or its absence, as appropriate. Configural theories can readily accommodate the present findings by assuming that there is temporal encoding of the feature cue. Hence, only portions of the feature cue closely preceding or overlapping the target stimulus are incorporated into the configural stimulus.

As may be apparent, the three types of theories are not mutually exclusive, and their mechanisms could operate concurrently. Recently, neural network models have been used to capture the thrust of each theory in a unified fashion (e.g., Schmajuk, Lamoureux, \& Holland, 1998; Zackheim, Myers, \& Gluck, 1998). In brief, these theories assume that responding to a feature-target compound is determined by both direct, single-layer linkages and indirect, hidden-layer linkages between input and output units. The influence of the hidden-layer units on output units can be construed as having a modulatory effect or a hierarchical effect, and the ability of the hidden units to combine different stimulus inputs can be construed as configural effects.

To obtain the temporal features of conditional discriminations, neural network models have borrowed from real-time models of conditioning (Desmond, 1990; Desmond \& Moore, 1988; Grossberg \& Schmajuk, 1989; Kehoe, Horne, \& Macrae, 1995; Sutton \& Barto, 1990). According to many real-time models, a CS is encoded as a cascade of hypothetical stimulus elements. Each element is assumed to acquire its own associative strength according to its contiguity with the US. The elicitation and timing of the CR depend on the summation of the associative strengths of overlapping elements. Successive portions of a feature cue generate their own stimulus elements that are combined with those of the target stimulus and acquire associative strength (Buhusi \& Schmajuk, 1999; Zackheim et al., 1998).

The devil is in the details of incorporating real-time assumptions into a neural network model of conditional discrimination. Real-time models assume that the cascade of stimulus elements diminishes over time, an assumption that real-time models share with older models that depict the temporal encoding of a stimulus as a decaying stimulus trace (Gormezano \& Kehoe, 1981; Hull, 1943; Kehoe et al., 1987; Pavlov, 1927, p. 39; Sutton \& Barto, 1981, 1990) or a short-term memory (Konorski \& Lawicka, 1959; Riley, Cook, \& Lamb, 1981; Roberts \& Grant, 1976). For example, Buhusi and Schmajuk (1999) assume that the elements immediately following stimulus onset have a large magnitude but a short duration, whereas later elements are progressively smaller but have longer durations. This pattern in the time course of the stimulus elements allows real-time models to explain two key of effects of CS-US interval manipulations: (1) the contiguity gradient, which is the decrease in the rate and level of CR acquisition as the CS-US interval is increased beyond an optimal value (e.g., Gormezano, Kehoe, \& Marshall, 1983; Kehoe, Cool, \& Gormezano, 1991), and (2) the scalar nature of response timing, which includes the proportional increase in the variability in the location of the CR's peak around the time of US presentation as the CS-US interval is increased (e.g., Gibbon, 1977, 1991; White, Kehoe, Choi, \& Moore, 2000).

The temporal limit of stimulus encoding has traditionally been identified by the disappearance of CR acquisition at longer CS-US intervals. For the rabbit NM response, CR acquisition ceases when the CS-US interval exceeds more than a few seconds (Gormezano et al., 1983; Kehoe et al., 1991). Even heart rate conditioning in the rabbit appears to have an outer boundary in CS-US intervals of somewhere between 20 and $45 \mathrm{sec}$ (Kehoe et al., 2000; Schneiderman, 1972). However, the as- 
sumption of decay conflicts with the pervasive observation that feature cues readily acquire conditional control over responding at very long intervals. In the rabbit NM preparation, feature-target intervals as long as $61 \mathrm{sec}$ have been used successfully (Macrae \& Kehoe, 1995).

A solution to this conflict might be found in the scalar nature of response timing. Although the acquisition of conditional discriminations occurs across a huge range of feature-target intervals, the gradients obtained in testing the feature-target intervals show a scalar pattern. In previous studies of conditional discriminations, rabbits trained with longer feature-target intervals showed broader gradients than did groups trained with shorter intervals (Kehoe et al., 2000). Similarly, in Experiment 1 of the present study, the gradients appeared more sharply defined around the 5-sec test interval than around the 45 -sec test interval.

The scalar property of timing would appear to reflect increasing variability in the stimulus encoding as time increases (Buhusi \& Schmajuk, 1999; Grossberg \& Schmajuk, 1989). By relying more on this variability and less on the decay in the stimulus encoding, real-time models may be able to explain both the conventional contiguity gradients in CR acquisition and the seemingly unbounded range of effective feature-target intervals in conditional discriminations. That is, successive portions of an encoding may decay more slowly than previously thought but would be increasingly variable in time. Progressive variability in the stimulus encoding would prevent $C R$ acquisition to the feature cue by itself, because, at longer CS-US intervals, no single subset of elements would accumulate enough associative strength at any one time to elicit an overt CR. Nevertheless, enough of the feature cue's elements would be active at any one time to be able to act jointly with the elements of the target stimulus, which would be less variable.

\section{REFERENCES}

Asraty an, E. A. (1965). Compensatory adaptations, reflex activity and the brain. Oxford: Pergamon.

Barnet, R. C., \& Miller, R. R. (1996). Temporal encoding as a determinant of inhibitory control. Learning \& Motivation, 27, 73-91.

Bouton, M. E. (1991). Context and retrieval in extinction and in other examples of interference in simple associative learning. In L. Dachowski \& C. F. Flaherty (Eds.), Current topics in animal learning: Brain, emotion, and cognition (pp. 25-49). Hillsdale, NJ: Erlbaum.

Brandon, S. E., \& WAgner, A. R. (1991). Modulation of a discrete Pavlovian conditioned reflex by a putative emotive Pavlovian conditioned stimulus. Journal of Experimental Psychology: Animal Behavior Processes, 17, 299-311.

Buhusi, C. V., \& SchmajuK, N. A. (1999). Timing in simple conditioning and occasion setting: A neural network approach. Behavioural Processes, 45, 33-57.

Desmond, J. E. (1990). Temporal adaptive responses in neural models: The stimulus trace. In M. Gabriel \& J. W. Moore (Eds.), Learning and computational neuroscience (pp. 421-456). Cambridge, MA: MIT Press.

Desmond, J. E., \& Moore, J. W. (1988). Adaptive timing in neural networks: The conditioned response. Biological Cybernetics, 58, 405415.

GibBon, J. (1977). Scalar expectancy theory and Weber's law in animal timing. Psychological Review, 84, 279-325.
Gibbon, J. (1991). Origins of scalar timing. Learning \& Motivation, 22 3-38.

Gibbs, C. M., Cool, V., Land, T., Kehoe, E. J., \& Gormezano, I. (1991). Second-order conditioning of the rabbit's nictitating membrane response: Interstimulus interval and frequency of CS-CS pairings. Integrative Physiological \& Behavioral Science, 26, 282-295.

Gibis, C. M., Kehoe, E. J., \& Gormezano, I. (1991). Conditioning of the rabbit's nictitating membrane response to a CSA-CSB-US serial compound: Manipulations of CSB's associative character. Journal of Experimental Psychology: Animal Behavior Processes, 17, 423-432.

GLUCK, M. A., \& Bower, G. H. (1988). Evaluating an adaptive network model of human learning. Journal of Memory \& Language, 27, 166195.

Gormezano, I. (1966). Classical conditioning. In J. B. Sidowski (Ed.), Experimental methods and instrumentation in psychology (pp. 385420). New York: McGraw-Hill.

Gormezano, I., \& GibBS, C. M. (1988). Transduction of the rabbit's nictitating membrane response. Behavior Research Methods, Instruments, \& Computers, 20, 18-21.

Gormezano, I., \& Kehoe, E. J. (1981). Classical conditioning and the law of contiguity. In P. M. Harzem \& M. D. Zeiler (Eds.), Advances in analysis of behavior: Vol. 2. Predictability, correlation, and contiguity (pp. 1-45.). New York: Wiley.

Gormezano, I., Kehoe, E. J., \& Marshall, B. S. (1983). Twenty years of classical conditioning research with the rabbit. In J. M. Sprague \& A. N. Epstein (Eds.), Progress in psychobiology and physiological psychology (Vol. 10, pp. 197-275). New York: Academic Press.

Grahame, N. J., Barnet, R. C., \& Miller, R. R. (1992). Pavlovian conditioning in multiple contexts: Competition between contexts for comparator status. Animal Learning \& Behavior, 20, 329-338.

Grahame, N. J., Hallam, S. C., Geier, L., \& Miller, R. R. (1990). Context as an occasion setter following either CS acquisition and extinction or CS acquisition alone. Learning \& Motivation, 21, 237 265.

Grossberg, S., \& Schmajuk, N. A. (1989). Neural dynamics of adaptive timing and temporal discrimination during associative learning. Neural Networks, 2, 79-102.

Holland, P. C. (1983). Occasion-setting in Pavlovian feature positive discriminations. In M. L. Commons, R. J. Herrnstein, \& A. R. Wagner (Eds.), Quantitative analyses of behavior: Discrimination processes (Vol. 4, pp. 182-206). New York: Ballinger.

Holland, P. C. (1992). Occasion setting in Pavlovian conditioning. In D. L. Medin (Ed.), The psychology of learning and motivation (Vol. 28, pp. 69-125). San Diego: Academic Press.

Holland, P. C., Hamlin, P. A., \& Parsons, J. P. (1997). Temporal specificity in serial feature-positive discrimination learning. Journal of Experimental Psychology: Animal Behavior Processes, 23, 95 109.

Hull, C. L. (1943). Principles of behavior. New York: Appleton-CenturyCrofts.

JAMES, J. H., \& WAGNER, A. R. (1980). One-trial overshadowing: Evidence of distributive processing. Journal of Experimental Psychology: Animal Behavior Processes, 6, 188-205.

KeHOE, E. J. (1998). Can the whole be something other than the sum of its parts? In C. D. L. Wynne \& J. E. R. Staddon (Eds.), Models of action: Mechanisms for adaptive behavior (pp. 87-126). Mahwah, NJ: Erlbaum.

Kehoe, E. J., Cool, V., \& Gormezano, I. (1991). Trace conditioning of the rabbit's nictitating membrane response as a function of CS-US interstimulus interval and trials per session. Learning \& Motivation, 22, 269-290.

Kehoe, E. J., Feyer, A.-M., \& Moses, J. L. (1981). Second-order conditioning of the rabbit's nictitating membrane response as a function of the CS2-CS1 and CS1-US intervals. Animal Learning \& Behavior, 9, 304-315.

Kehoe, E. J., Gibbs, C. M., Garcia, E. \& Gormezano, I. (1979). Associative transfer and stimulus selection in classical conditioning of the rabbit's nictitating membrane response to serial compound CSs. Journal of Experimental Psychology: Animal Behavior Processes, $\mathbf{5}$, 1-18.

Kehoe, E. J., Horne, A. J., \& Macrae, M. (1995). Learning to learn: 
Real-time features and a connectionist model. Adaptive Behavior, $\mathbf{3}$, 235-271.

Kehoe, E. J., Marshall-Goodell, B., \& Gormezano, I. (1987). Differential conditioning of the rabbit's nictitating membrane response to serial compound stimuli. Journal of Experimental Psychology: Animal Behavior Processes, 13, 17-30.

Kehoe, E. J., Palmer, N., Weidemann, G., \& Macrae, M. (2000). The effect of feature-target intervals in conditional discriminations on acquisition and expression of conditioned nictitating membrane and heart rate responses in the rabbit. Animal Learning \& Behavior, 28 , $80-91$.

Kimmel, H. D., \& RAY, R. L. (1978). Transswitching: Conditioning with tonic and phasic stimuli. Journal of Experimental Psychology: General, 107, 187-205.

KoNORSKI, J. (1967). Integrative activity of the brain: An interdisciplinary approach. Chicago: University of Chicago Press.

KonORSKI, J., \& LAWICKA, W. (1959). Physiological mechanisms of delayed reactions: 1 . The analysis and classification of delayed reactions. Acta Biologiae Experimentalis, 19, 175-197.

Macrae, M., \& Kehoe, E. J. (1995). Transfer between conditional and discrete discriminations in conditioning of the rabbit nictitating membrane response. Learning \& Motivation, 26, 380-402.

O'Brien, R. G., \& KaISER, M. K. (1985). MANOVA method for analyzing repeated measures designs: An extensive primer. Psychological Bulletin, 97, 316-333.

Pavlov, I. P. (1927). Conditioned reflexes: An investigation of the physiological activity of the cerebral cortex (G. V. Anrep, Trans.). London: Oxford University Press.

Pearce, J. M. (1987). A model for stimulus generalization in Pavlovian conditioning. Psychological Review, 94, 61-73.

Pearce, J. M. (1994). Similarity and discrimination: A selective review and a connectionist model. Psychological Review, 101, 587-607.

RazRAN, G. (1971). Mind in evolution. New York: Houghton-Mifflin.

Rescorla, R. A. (1973). Evidence for "unique stimulus" account of configural conditioning. Journal of Comparative \& Physiological Psychology, 85, 331-338.

RESCORLA, R. A. (1985). Inhibition and facilitation. In R. R. Miller \& N. E. Spear (Eds.), Information processing in animals: Conditioned inhibition (pp. 299-326). Hillsdale, NJ: Erlbaum.

Riley, D. A., COOK, R. G., \& LAMB, M. R. (1981). A classification and analysis of short-term retention codes in the pigeon. In G. H. Bower (Ed.), The psychology of learning and motivation: Advances in research and theory (Vol. 15, pp. 51-79). New York: Academic Press.

RoberTs, W. A., \& Grant, D. S. (1976). Studies of short-term memory in the pigeon using the delay matching-to-sample procedure. In D. L. Medin, W. A. Roberts, \& R. T. Davis (Eds.), Processes of animal memory (pp. 79-112). Hillsdale, NJ: Erlbaum.

Savastano, H. L., \& Miller, R. R. (1998). Time as content in Pavlovian conditioning. Behavioural Processes, 44, 147-162.
Scandrett, J., \& Gormezano, I. (1980). Microprocessor control and A/D data acquisition in classical conditioning. Behavior Research Methods \& Instrumentation, 12, 120-125.

Schmajuk, N. A., Lamoureux, J. A., \& Holland, P. C. (1998). Occasion setting: A neural network approach. Psychological Review, 105, $3-32$.

Schneiderman, N. (1972). Response system divergencies in aversive classical conditioning. In A. H. Black \& W. F. Prokasy (Eds.), Classical conditioning: Current research and theory (pp. 341-376). New York: Appleton-Century-Crofts.

Schreurs, B. G., Kehoe, E. J., \& Gormezano, I. (1993). Concurrent associative transfer and competition in serial conditioning of the rabbit's nictitating membrane response. Learning \& Motivation, 24, 395 412.

Sutton, R. S., \& Barto, A. G. (1981). Toward a modern theory of adaptive networks: Expectation and prediction. Psychological Review, 88, 135-171.

Sutton, R. S., \& Barto, A. G. (1990). Time-derivative models of Pavlovian reinforcement. In M. Gabriel \& J. W. Moore (Eds.), Learning and computationalneuroscience (pp. 497-537). Cambridge, MA: MIT Press.

Wagner, A. R., \& Brandon, S. E. (1989). Evolution of a structured connectionist model of Pavlovian conditioning (AESOP). In S. B. Klein \& R. R. Mowrer (Eds.), Contemporary learning theories: Pavlovian conditioning and the status of traditional learning theory (pp. 149-190). Hillsdale, NJ: Erlbaum.

Weidemann, G., Georgilas, A., \& Kehoe, E. J. (1999). Temporal specificity in patterning of the rabbit nictitating membrane response. Animal Learning \& Behavior, 27, 99-107.

Weidemann, G., \& Kehoe, E. J. (1997). Transfer and counterconditioning of conditional control in the rabbit nictitating membrane response. Quarterly Journal of Experimental Psychology, 50B, 295316.

White, N. E., Kehoe, E. J., Choi, J.-S., \& Moore, J. W. (2000). Coefficients of variation in timing of the classically conditioned eyeblink in rabbits. Psychobiology, 28, 520-524.

Whit LOW, J. W., JR., \& WAGNER, A. R. (1972). Negative patterning in classical conditioning: Summation of response tendencies to isolable and configural components. Psychonomic Science, 27, 299-301.

Zackheim, J., Myers, C., \& Gluck, M. (1998). A temporally sensitive recurrent network model of occasion setting. In N. Schmajuk \& P. Holland (Eds.), Occasion setting: Associative learning and cognition in animals (pp. 319-342). Washington, DC: American Psychological Association.

(Manuscript received November 7, 2000; revision accepted for publication January 8, 2002.) 